\title{
ANALISA PERANCANGAN DAN IMPLEMENTASI PEMESANAN SECARA ONLINE BERBASIS COSTUMER RELATIONSHIP MANAGEMENT (CRM)
}

\author{
Aggy Pramana Gusman \\ Universitas Putra Indonesia YPTK Padang \\ apgusman@gmail.com
}

\begin{abstract}
The development of internet technology and the ease of access of various communication equipment, have an influence on the style of consumers to shop effectively and efficiently. Web-based electronic commerce in business competition requires more creative and innovative ways to better indulge consumers to remain loyal. Therefore the Costomer Relationship Management (CRM) method is determined by the company to get as many costomers as possible in order to establish good relationships with consumers. Istana Karpet dan Perabot is one of the companies engaged in the sale of furniture. In the process of ordering as long as this happens it is done by the way consumers come directly to the store. The system that has been used often creates obstacles in the process of providing information about the latest products and making orders. In overcoming this problem, the Istana Karpet dan Perabot requires a computational system that is able to introduce its products and place orders online.
\end{abstract}

Keywords: CRM, PHP, Web, Teknologi Internet, Furniture.

\section{Pendahuluan}

Perkembangan dunia informasi dari waktu ke waktu terus mengalami peningkatan dan perkembangan. Kegiatan di semua bidang mengharuskan segalanya di lakukan dengan cepat dan akurat maka diperlukan sebuah teknologi informasi hal tersebut didukung dengan berkembangnya teknologi yang semakin maju dan memadai. Sehingga informasi dapat di akses secara cepat, tepat, terkini, serta akurat. Selain berdasarkan pada hal tersebut, penyajian suatu informasi juga perlu mendapatkan perhatian serius untuk menarik konsumen.Toko Istana Karper dan Perabot merupakan salah satu perusahaan yang bergerak dalam bidang furniture. Dalam proses promosi dan pemesanan terhadap produk baru yang selama ini terjadi dilakukan dengan cara konsumen datang ke toko lalu karyawan akan memperkenalkan produk-produk yang terdapat di Toko Istana Karpet dan Perabot, kemudian konsumen membuat daftar barang yang akan dipesan dan dicatat secara manual.

Sistem yang selama ini terjadi sering menimbulkan kendala dalam proses promosi dan pemesanan yang merepotkan konsumen untuk datang ke toko. Dalam mengatasi permasalahan seperti ini, maka Toko Istana Karpet dan Perabot memerlukan sebuah sistem terkomputerisasi yang mampu memperkenalkan produk-produknya dan melakukan pemesanan secara online untuk mengembangkan sistem yang selama ini dipakai.

\section{LANDASAN TEORI}

\subsection{Konsep Dasar Sistem Informasi}

Sistem informasi dapat didefenisikan sebagai suatu sistem dalam suatu organisasi yang merupakan kombinasi dari orang-orang, fasilitas, teknologi, media, prosedur-prosedur, dan pengendalian yang ditujukan untuk mendapatkan jalur komunikasi penting, memproses tipe transaksi rutin tertentu, memberi sinyal kepada manajemen dan yang lainnya terhadap kejadian-kejadian internal dan eksternal yang penting dan menyediakan suatu dasar informasi untuk pengambilan keputusan yang baik.

Sistem informasi dapat dianalogikan sebagai sebuah permintaan (demand) dari masyarakat industri, ketika kebutuhan akan sarana pengolahan data dan komununikasi yang cepat dan murah (menembus ruang waktu).

\subsection{Costomer Relationship Management}

Costumer Relationship Management adalah proses keseluruhan untuk membangun dan menjaga hubungan dengan pelanggan melalui pemberian nilai pelanggan superior dan kepuasan pelanggan 


\subsubsection{Tujuan Costomer Relationship Management}

Pada dasarnya, tujuan suatu CRM adalah untuk meningkatkan ketahanan dan kepuasan pelanggan. Secara umum dapat dikatakan bahwa tujuan setiap strategi CRM adalah untuk mengembangkan hubungan yang menguntungkan dengan pelanggan.

\subsubsection{Manfaat Costomer Relationship Management}

Manfaat Costomer Relationship Management adalah :

a. Mendorong loyalitas pelanggan

b. Mengurangi biaya

c. Meningkatkan efisiensi operasional

d. Peningkatan time to market

e. Peningkatan pendapatan

\section{$2.3 U M L$}

UML (Unified Modeling Language) adalah salah satu standar bahasa yang banyak digunakan di dunia industri untuk mendefinisikan requirement, membuat analisis dan disain, serta menggambarkan arsitektur dalam pemrograman berorientasi objek.

\subsection{MySQL}

MySQL merupakan software yang tergolong sebagai DBMS (Database Management Sistem) yang bersifat open source. MySQL termasuk dalam kategori database management sistem, yaitu suatu database yang terstruktur dalam pengolahan dan penampilan datanya. MySQL merupakan database yang bersifat client server, dimana data diletakkan di server yang bisa di akses melalui komputer client. Pengaksesan dapat dilakukan apabila komputer telah terhubung dengan server.

MYSQL merupakan database yang dikembangkan dari bahasa SQL (Structure Query Language). SQL merupakan bahasa terstruktur yang digunakan untuk interaksi antara script program dengan database server dalam hal pengolahan data. Dengan SQL maka dapat dibuat tabel yang akan diisi data, memanipulasi data seperti menambah, menghapus dan meng-update dataserta membuat suatu perhitungan berdasarkan data yang ditemukan.

SQL tidak hanya terbatas digunakan untuk mendapat suatu tampilan database statis, namun juga dikembangkan SQL yang berencana membuat SQL menjadi bahasa yang mendekati mesin turing misalnya computable query atau recursive query.

\subsection{PHP}

PHP merupakan bahasa pemrograman skrip yang diletakkan dalam server yang biasa digunakan untuk mambuat aplikasi web yang bersifat dinamis. PHP (PHP hypertext processor) adalah bahasa scripting server-side bagi pemrograman web. Secara sederhana, PHP merupakan tool bagi pengembang web dinamis.PHP sangat popular karena memiliki fungsi built-in lengkap. Cepat, mudah dipelajari, dan bersifat gratis. Skrip PHP cukup disisipkan pada kode HTML agar dapat bekerja. PHP dapat berjalan di berbagai web server dan sistem operasi yang berbeda.

PHP mendukung berbagai database. Termasuk yang didukungnya adalah MySQL. Dengan demikian database yang anda buat dengan MySQL dapat diakses oleh PHP dan memungkinkan untuk menampilkan isinya atau bahkan memanipulasi datanya melaui halaman web. PHP bekerja sebagai interpreter. Oleh karena itu, php memerlukan kode asli (yang biasa disebut sebagai kode sumber atau sourcecode). Ketika seseorang melalui browser meminta sebuah program berekstensi php, web browser yang bertanggung jawab menanganinya segera mengambil kode sumber PHP-nya dan menyerahkan ke interpreter PHP. Selanjutnya, interpreter PHP segera mengeksekusi kode dan menyerahkan hasilnya ke webserver, lalu webserver menyerahkan kode yang dihasilkan oleh interpreter PHP ke pemakai yang memintanya.

Kode inilah yang selanjutnya diterjemahkan oleh browser untuk ditampilkan ke layar. Pada saat mengeksekusi kode, PHP akan berkomunikasi ke databaseserver (misalkan MySQL) sekiranya kode mengandung perintah untuk mengakses database. 


\section{ANALISA DAN PERANCANGAN}

\subsection{Analisa Sistem}

Dalam membangun sistem, tahap analisa sistem dilakukan sebelum tahap perancangan sistem. Tahap analisa sistem merupakan tahap yang penting dalam perancangan suatu sistem, karena kesalahan didalam tahap ini akan menyebabkan kesalahan di dalam tahap selanjutnya. Dalam tahap analisa sistem, penulis menganalisa untuk menemukan kelemahan-kelemahan pada sistem yang sedang berjalan pada suatu organisasi atau perusahaan dengan tujuan agar sistem tersebut dapat diusulkan perbaikannya.

\subsubsection{Analisa Sistem Sedang Berjalan}

Adapun aliran kerja sistem lama pada Toko Ruminansia adalah sebagai berikut :

a. Belum adanya sebuah sistem berbasis website yang dapat mempromosikan dan penjualan produkproduk yang ada pada Toko Istana Karpet dan Perabot

b. Belum adanya data yang tersimpan dalam sebuah database untuk memudahkan Toko Istana Karpet dan Perabot dalam menyimpan data pemesanan tersebut dapat tersimpan lebih aman.

\subsubsection{Usulan Sistem Baru}

Berdasarkan identifikasi masalah yang ada pada bab sebelumnya maka ditemui kelemahan pada sistem yang lama, antara lain :

a. Belum adanya sistem yang memperkenalkan produk secara online.

b. Penyimpanan data yang masih dalam dokumen dokumen tidak efektif dan efisien karena memakan memakan waktu lama dalam pencarian serta mudah hilang atau rusak.

\subsubsection{Desain Global}

Desain global atau yang sering disebut desain makro sistem merupakan desain yang mengambarkan atau memberikan gambaran secara umum kepada user tentang sistem yang akan dibangun dan informasi-informasi apa saja yang akan dihasilkan dari sistem baru yang dibangun. Desain sistem secara global ini dilakukan sebagai persiapan untuk membangun atau mendesain sistem secara terinci dengan alternatif-alternatif terluas dari suatu perancangan.

\subsubsection{Use Case Diagram}

Use case diagram menjelaskan manfaat dari aplikasi jika dilihat dari sudut pandang orang yang berada diluar sistem (aktor).

Adapun Use Case Diagram pada Istana Karpet dan Perabot dapat dilihat seperti Gambar 3.1 sebagai berikut:

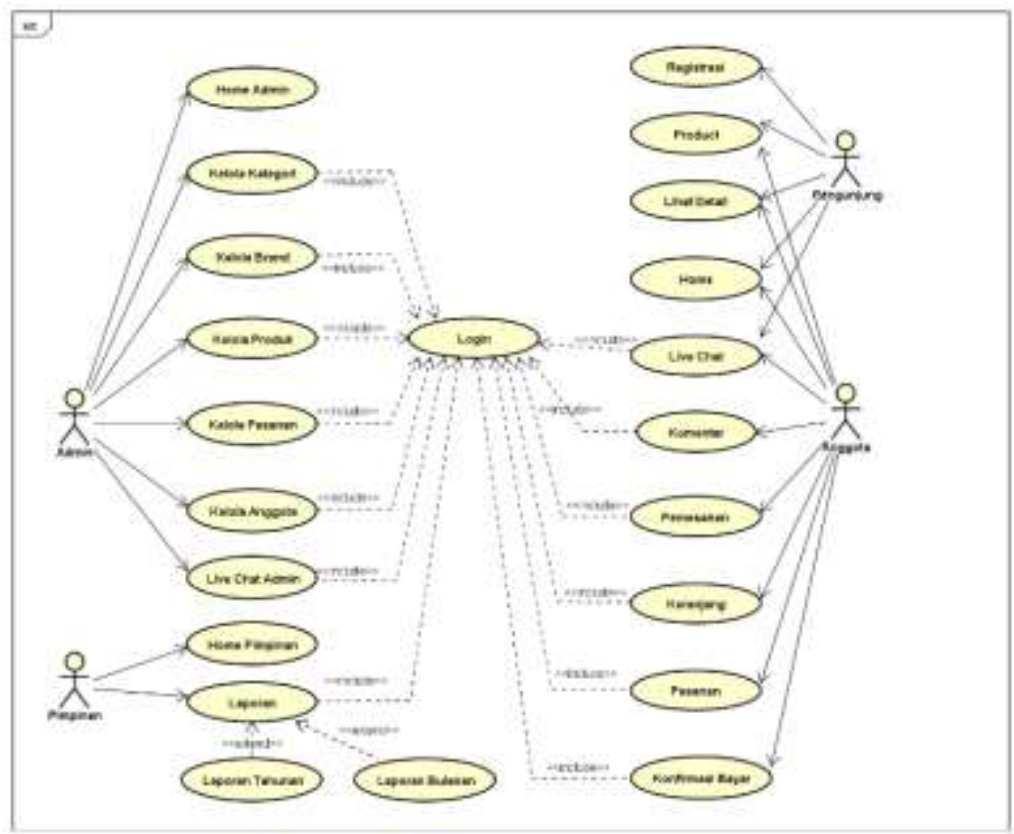

Gambar 3.1: Use Case Diagram 


\subsubsection{Class Diagram}

Class diagram merupakan himpunan dari objek-objek yang memiliki struktur sama, serta memiliki prilaku dan relasi yang sama pula

Adapun Class Diagram padaToko Istana Karpet dan Perabot dapat dilihat seperti Gambar 3.2 sebagai berikut:

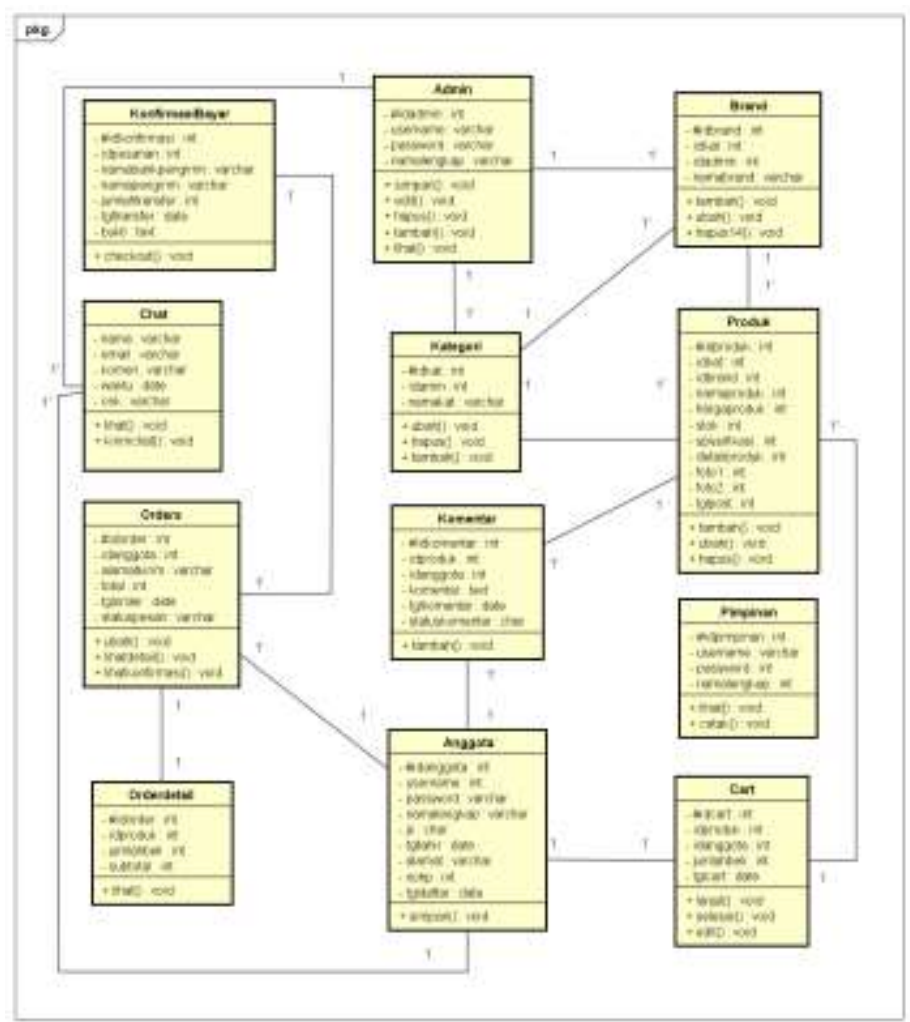

Gambar 3.2: Class Diagram

\section{IMPLEMENTASI DAN PENGUJIAN SISTEM}

\subsection{Implementasi Sistem}

Implementasi istem adalah tahap penerapan sistem yang akan dilakukan jika sistem disetujui termasuk program yang telah dibuat pada tahap perancangan sistem agar siap untuk di operasikan.

Agar implementasi berjalan dengan baik dan lancar, maka suatu rencana implementasi perlu dibuat terlebih dahulu. Rencana ini dimaksudkan untuk mengatur biaya serta waktu yang dibutuhkan selama tahap implementasi.

\subsection{Pengujian Sistem}

\subsubsection{Halaman Awal}

Halaman awal adalah tampilan pertama kali yang akan tampil yang diakses oleh konsumen atau anggota tanpa harus login, dapat dilihat gambar 4.1 berikut : 


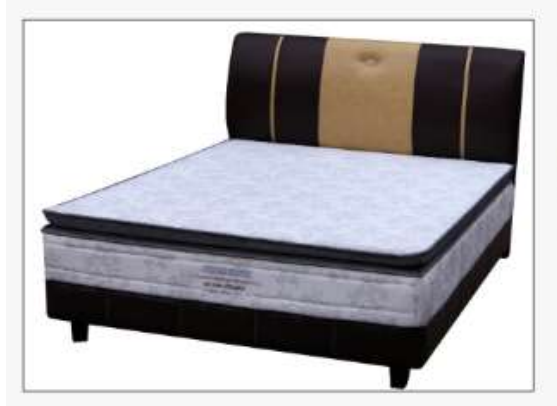

\section{BED SET SINGLE PILLOW TOP}

Tersedia 2 Unit

Deskripsi :

Springbed + Divan + Sandaran

Lihat Delail Beli Sekarang

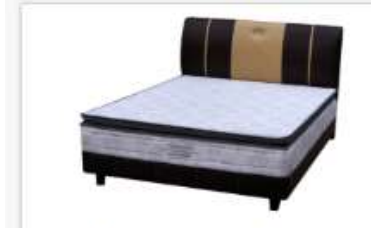

BED SET SINGLE PILLOW TOP...

Rp. 49000000

Tersedia 2 Unit

Lhat Bell

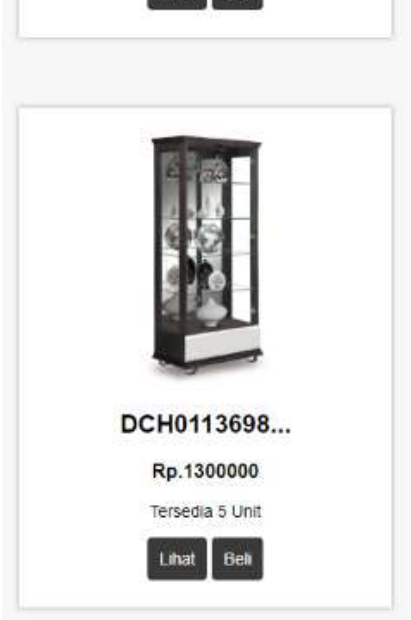

| Istana Karpet Dan Perabot Tentang Kami
Hubungi Kami Hubungi Kami
Lokasi Toko

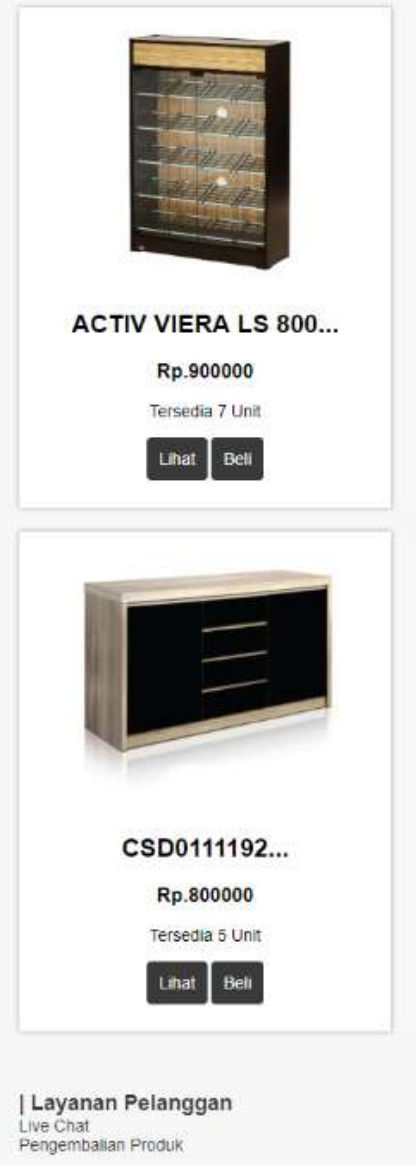

Live Chat

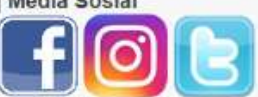

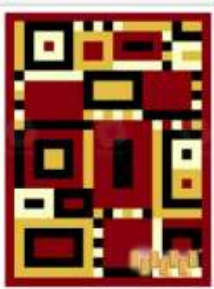

MODERNO BRWN...

Rp. 450000

Tersedia 10 unit

Lithat Bell

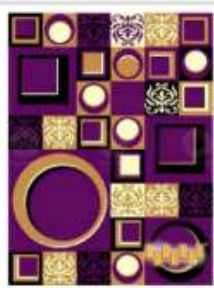

MODERNO LVNDR..

Rp.450000

Tersecla 4 Unit

Lithat Beli

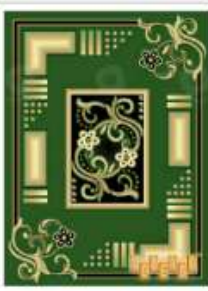

MODERNO GRN..

Rp. 450000

Tersedia 7 Unit Linat Bell

Gambar 4.1: Halaman Awal

\subsubsection{Halaman Laporan Bulanan}

Desain laporan bulanan yang akan ditampilkan pada pimpinan, dapat dilihat seperti gambar 4.2 berikut: 


\section{TOKO ISTANA KARPET DAN PERABOT}

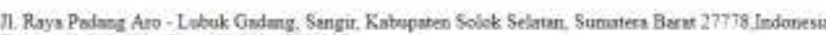

Tthe : +02 $819-629-431 /-52812-6790-00 \%$

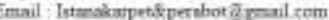

Laporan Bulan 12 Tahun 2018

\begin{tabular}{|c|c|c|c|c|}
\hline Ne. & Mama Pemesan & Nama Proouk & Taneger & Scentot: \\
\hline 1 & Etoralira Gratno & BED SET SANGLE PILLOW TOP. & $(2018-12-2)$ & 49006000 \\
\hline \multicolumn{4}{|c|}{ Total } & +0000050 \\
\hline
\end{tabular}

Gambar 4.2: Desain Laporan Bulanan

\subsubsection{Halaman Laporan Tahunan}

Desain laporan tahunan yang akan ditampilkan pada pimpinan, dapat dilihat seperti gambar 4.3 berikut:

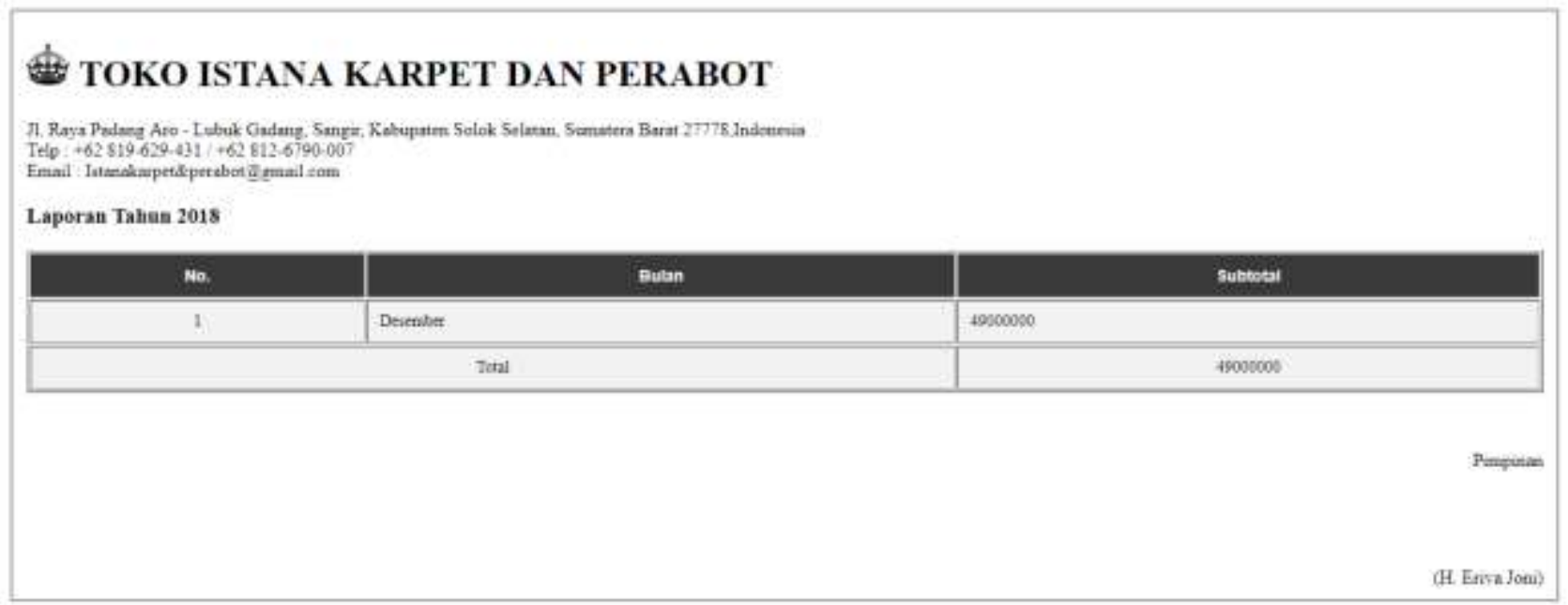

Gambar 4.2: Desain Laporan Tahunan

\section{KESIMPULAN}

Berdasarkan hasil pengamatan dan analisa perancangan sistem yang telah dilakukan maka dapat diambil beberapa kesimpulan yaitu :

a. Aplikasi pemesanan secara online berbasis CRM pada Toko Istana Karpet dan Perabot dapat mempermudah konsumen memesan dan mendapatkan informasi yang dibutuhkan kapanpun dan dimanapun.

b. Aplikasi pemesanan secara online berbasis CRM pada Toko Istana Karpet dan Perabot dapat meningkatkan efisiensi dan keuntungan pada Toko Istana Karpet dan Perabot.

c. Aplikasi pemesanan secara online berbasis CRM pada Toko Istana Karpet dan Perabot dapat memberikan kemudahan untuk konsumen tanpa harus datang ke Toko Istana Kapet dan Perabot.

\section{DAfTAR PUStaka}

[1] Andini, S. dan Ramadhany F. (April, 2018). Perancangan Aplikasi Sistem Pendukung Keputusan Pemilihan Telur Yang Baik Untuk Dikonsumsi Ibu Hamil Menggunakan Metode Simple Additive Weight (SAW) Berbasis Web. Vol 8, No. 1, E-ISSN : 2541-1535, hal. 37

[2] Andrinof, Harkamsyah. (Maret, 2018). Rancang Bangun Sistem Informasi Promosi Dan Penjualan Pada Toko Ruminansia Berbasis Web.Vol 5, No. 1, E-ISSN : 2355-997, hal. 13 
[3] Afrina, M., Diyantina, O., Ibrahim A. (Oktober, 2012). Penerapan Costomer Relationship (CRM) Berbasis Web (Studi Kasus Pada Sistem Informasi Pemasaran di Toko Yen-Yen).Vol 4, No. 2, E-ISSN : 2355-4614, hal. $519-520$

[4] A. S. Rosa dan M. Shalahuddin, 2014. Rekayasa Perangkat Lunak Terstruktur dan Berorientasi Objek. Bandung: Informatika

[5] Gusman, A. P. (September, 2015). Sistem Pakar Untuk Mendiagnosa Gangguan Autis Pada Anak Dengan Metode Forward Chaining. Vol 2, No. 1, ISSN : 2355-9977, hal. 25-42

[6] Gushelmi. (Oktober, 2012). Pemodelan UML Sistem Penerimaan Mahasiswa Baru Berbasis WAP (Studi Kasus : Sistem Penerimaan Mahasiswa Baru UPI "YPTK" Padang).Vol 1, No. 1, hal. 24-44

[7] Hasugian, P. S. (Maret, 2018). Perancangan Website Sebagai Media Promosi Dan Informasi.Vol 8, No. 1, E-ISSN : 2541-3724, hal. 83

[8] Putra, Y. A., Sumijan, Mardison (April, 2018). Perancangan Sistem Informasi Akademik Menggunakan Bahasa Pemrograman PHP Dan Database Mysql (Studi Kasus Paud Terpadu Bismillah Kota Bukittinggi).Vol 8, No. 1, E-ISSN : 2541-1535, hal. 26

[9] Siregar, V. M. M. (April, 2018). Perancangan Website Sebagai Media Promosi Dan Penjualan Produk. Vol 9, No. 1, E-ISSN : 2579-4221, hal. 16

[10] Sirait, D. P. (April, 2018). Pengaruh Costomer Relationship Management Dan Kualitas Pelayanan Terhadap Kepuasan Pelanggan.Vol 3, No. 1, ISSN : 2338-123X, hal. 37

[11] Surmayanti. (April, 2016). Sistem Informasi Obyek Wisata Pulau Pamutusan.Vol 3, No. 1, E-ISSN : 2502-8758, hal. 93-94

[12] Thjin, B. A. (September, 2014). Pengembangan Model Sistem Informasi Pemesanan Paket Wisata Pada Pt Sakabahari Travel Jakarta. Vol 16, Paradigma, hal. 35-36 